\title{
ANALISIS SELF MANAGEMENT DAN PENGONTROLAN TEKANAN DARAH PADA PASIEN HIPERTENSI PADA MASA PANDEMI COVID -19 DI PUSKESMAS LIMA PULUH KOTA PEKANBARU
}

\author{
Desti Puswati ${ }^{1}$, Novi Yanti ${ }^{2}$, Dekriani Yuzela ${ }^{3}$ \\ 1,2,3 STIKes Payung Negeri Pekanbaru \\ ${ }^{1}$ Email : destippus@gmail.com
}

Diterima: Juni 2021, Diterbitkan: Juni 2021

\begin{abstract}
ABSTRAK
Akibat adanya pandemi covid-19 untuk mencegah penularan pengontrolan tekanan darahpada pasien hipertensi yang biasanya dilakukan di Puskesmas dianjurkan untuk dilakukan sendiri di rumah.Sehingga perlu self manajement yang baik selama pandemic pada penderita hipertensi agar tidak kambuh. Kasus tertinggi hipertensi ke 3 di kota Pekanbaru adalah wilayah Puskesmas Lima Puluh Kota. Tujuan penelitian ini adalah untuk menganalisis Self Management dan pengontrolan tekanan darah pada pasien hipertensi di Puskesmas Lima Puluh Kota Pekanbaru. Penelitian dilakukan terhadap 66 pasien dengan hipertensi dengan teknik probability sampling. Penelitian menggunakan desain deskriptif yaitu analisis self manajemen dan pengontrolan tekanan darah. Alat ukur yang digunakan adalah kuesioner Hypertension Self Manajement Behavoir Quetionnaire (HSMBQ) dan instrument pengukuran tekanan darah pasien satu bulan terkhir. Uji statistic yang digunakan adalah distribusi frekwensi. Hasil diperoleh self management dalam kategori sedang 66,7 \% dan pengontrolan tekanan darah pada pasien hipertensi mayoritas tidak terkontrol yaitu $68,2 \%$. Saran untuk
\end{abstract}

Kata kunci $\quad$ : Self Management, Pengontrolan Tekanan Darah, Hipertensi

\begin{abstract}
Due to the Covid-19 pandemic, blood pressure management control which is usually carried out at the Puskesmas is recommended to be measured or home monitored to prevent the transmission of Covid- 19. The third highest case which happened in Puskesmas Lima Puluh Kota is hypertension. The purpose of this study was to analyze hypertensive patient on Self Management and blood pressure monitoring at Puskesmas Lima Puluh Kota in Pekanbaru city. The descriptive desained study patient with hypertention involves 66respondent with probability sampling technique.The measuring instrument used was the Hypertension Self-Management Behavior Quetionnaire (HSMBQ, while the instrument for controlling blood pressure uses the measurement of the respondent's blood pressure in the last month. The statistical test used in this study is the frequency distribution. The resultsshowed that self management was moderate category $66.7 \%$ and blood pressurecontrol was in the majority of patients hypertension patients is not controlled, namely $68.2 \%$. Suggestions for health services to provide health education to patient with hypertension about self-management so that patients do not have a relapse who are at risk of being easily infected with covid 19
\end{abstract}

Keywords $\quad$ : Self Management, Blood Pressure Control, Hypertension 


\section{PENDAHULUAN}

Di Indonesia pada tanggal 19 Juni 2020 terdapat kasus Covid 19 sebanyak 17.349 kasus (Nugraheny, 2020). sedangkan pada tanggal 7 Agustus 2020, terdapat 121.226 kasus terkonfirmasi Covid 19 (Yahya, 2020) berarti meningkat $2.768 \%$ dalam jangka 3 bulan (Nugraheny, 2020). Terkait penyakit tersebut kelompok yang paling rentan dan kemudian memiliki peluang kematian yang tinggi adalah pada kelompok penyakit penyerta sebelumnya, seperti kanker diabetes militus, hipertensi (Faraby,2020). Berdasarkan data yang dihimpun oleh Satuan Tugas Penanganan COVID-19 per tanggal 13 Oktober 2020, dari total kasus yang terkonfirmasi positif COVID-19, sebanyak 1.488 pasien tercatat memiliki penyakit penyerta. Di mana presentase terbanyak adalah penyakit hipertensi sebesar 50,5\%. Rokom, (2021).

Menurut Departemen Kesehatan (2017) di Indonesia, prevelensi penderita hipertensi ialah terdapat sekitar $31,7 \%$, dimana hanya 7,2 dari $31,7 \%$ penduduk yang mempunyai pemahaman mengenai hipertensi serta terdapat kejadian yang minum obat hipertensi hanya sekitar 0,4\%.Risdiknakes (2018).

Arista (2013) mengemukakan bahwa bagi individu yang mempunyai faktor risiko hipertensi tersebut harus waspada serta melakukan upaya pencegahan sedini mungkin. Contoh yang sederhana yaitu dengan rutin kontrol tekanan darah lebih dari satu kali, dan juga berusaha untuk menghindari faktor pencetus seperti pola makan dan gaya hidup (live style) yang baik. Penderita hipertensi yang tidak menjaga pola makan dan gaya hidup yang sehat mempunyai risiko mengalami hipertensi berulang atau kekambuhan hipertensi. Kekambuhan hipertensi dipengaruhi oleh berbagai faktor baik dari dalam maupun dari luar lansia. Pasein dengan hipertensi selain mengalami gangguan secara fisiologis, pengobatan yang lama serta ancaman komplikasi dapat terjadi akan mengakibatkan pasien hipertensi terganggu secara psikologis, salah satunya adalah kecemasan (ansietas). Ansietas merupakan gangguan emosional yang kerap sering terjadi di Amerika Serikat. Setidaknya 17\% individu dewasa di Amerika Serikat, menunjukkan satu gangguan ansietas atau lebih dalam setahun. Stres menjadi faktor yang cenderung mengakibatkan terjadinya hipertensi (Khotimah, 2013). Stres bisa memicu timbulnya hipertensi melalui aktivitas sistem saraf simpatis yang mengakibatkan naiknya tekanan darah menjadi tidak menentu (Andria, 2013).

$$
\text { Strategi Pengelolaan Diri (Self }
$$

Management) merupakan teknik yang berakar pada teori pengkondisian operan. Tujuan dari strategi pengelolaan diri (Self Management) ini adalah supaya individu secara teliti dapat menempatkan diri dalam situasi- situasi yang menghambat tingkah laku dan belajar untuk mencegah timbulnya perilaku atau masalah yang tidak dikehendaki. Bentuk pelaksananaannya antara lain meliputi self monitoring (pemantauan diri), stimulus control (pengendalian diri), serta self reward (penghargaan diri sendiri). Penerapan teknik self management dengan mengkombinasikan beberapa teknik biasanya lebih berguna dari pada menggunakan satu teknik saja (Brillianti,2016).

Berdasarkan data yang didapat dari Dinas Kesehatan Kota Pekanbaru tahun 2019 dari 21 puskesmas di Kota Pekanbaru, Puskesmas Lima Puluh merupakan puskesmas dengan angka kejadian hipertensi 3 tertinggi di Kota Pekanbaru dengan jumlah 2.319 kasus. Berdasarkan hasil survei yang dilakukan di Puskesmas Lima Puluh Kota Pekanbaru dengan mewawancarai 10 orang dan 7 orang $(70 \%)$ mereka mengatakan 
belum pernah melakukan terapi Self Management untuk menurunkan tekanan darah. Mereka mengatakan menggunakan obat farmakologi anti hipertensi dan juga ada yang menggunakan terapi non farmakologi yang dilakukan seperti minum rebusan daun sirsak dan mengonsumsi mentimun.

\section{METODE PENELITIAN}

Jenis penelitian kuantitatif dengan menggunakan desain deskriptif, pendekatan Study Cross Sectional. Penelitian dilakukan di Puskesmas Lima Puluh Kota Pekanbaru yang mempunyai kasus ke-3 tertinggi di kota Pekanbaru. Penelitian dilaksanakan pada bulan Juni 2020 hingga Juni 2021, Populasi dalam penelitian ini adalah pasien dengan hipertensi sebanyak 193 orang dengan jumlah sampel penelitian 66 orang yang dihitung dengan rumus Slovin (Sugiyono, 2017), dengan teknik probability sampling sample diambil dari pasien hipertensi yang tercatat pada medical record Puskesmas Lima Puluh Kota Pekanbaru dan mempunyai kontak yang dapat dihubungi menggunakan whatsapp . Instrumen dalam penelitian ini menggunakan kuesioner Perilaku Manajemen Diri Hipertensi (Hypertention Self Management Behavior Quetionnaire (HSMBQ)) yang terdiri dari Kuesioner Selfefficacy to Manage Hypertension-Five Item Scale digunakan untuk variabel self-efficacy dengan lima item pernyataan. Hasil uji reliabilitas menunjukkan nilai Cronbach's Alpha yaitu 0,903. Hypertension Selfmanagement Behaviour Questionnaire (HSMBQ) digunakan untuk variabel selfmanagement behaviour dengan 32 item pernyataan. Hasil uji reliabilitas menunjukkan nilai Cronbach's Alpha yaitu 0,945, Agastia (2020) dan Instumen Pengontrolan tekanan darah menggunakan ukuran tekanan darah satu bulan terakhir. Pengumpulan data menggunakan kuesioner yang dikirim lewat whatsapp.

\section{HASIL DAN PEMBAHASAN}

Setelah dilakukan pengumpulan data dan pengolahan data maka didapatkan hasil sebagai berikut

Tabel 1

Distribusi Responden Berdasarkan

Usia Pada Pasien Hipertensi Di

Puskesmas Lima Puluh Kota

\begin{tabular}{l|l|l|l|}
\hline No & USIA & f & $\%$ \\
\hline 1 & $20-60$ & 60 & 90 \\
2 & $>60$ & 6 & 10 \\
\hline
\end{tabular}

Dapat dilihat pada Tabel.1 mayoritas responden berada pada usia kategori dewasa (20-60 tahun) sebanyak 60 responden $(90 \%)$ Usia 20-60 tahun merupakan usia dewasa menurut WHO 2020 (Harismi,2020). Dimana usia dewasa adalah saat individu mempunyai aktifitas yang tinggi dalam kehidupan yang membuat stres sehingga memudahkan untuk terjadinya hipertensi, Dimana penderita hipertensi kurang kebal terhadap stres (Andria, 2013). Pada usia lanjut terjadi penebalan pembuluh darah dan yang akan menurunkannya fleksibilitas kapiler, pembuluh darah menjadi kaku, berkurang keelastisitasannya, dan menebal. Rusaknya pembuluh darah menyebabkan jantung memompa darah lebih keras karena aliran darah yang masuk jantung berkurang, sehingga menyebabkan tekanan darah meningkat. Tekanan darah yang meningkat terus menerus akan menjadi persisten dan menyebabkan hipertensi. Irza (2009) dalam Herawati dan Wahyuni (2016).

Tabel 2

Distribusi Responden Berdasarkan Jenis Kelamin Pada Pasien Hipertensi Di Puskesmas Lima Puluh Kota

\begin{tabular}{llll}
\hline No & Jenis Kelamin & f & $\%$ \\
\hline 1 & Laki-laki & 28 & 42,4 \\
2 & Perempuan & 38 & 57,6 \\
\hline & Jml & 66 & 100 \\
\hline
\end{tabular}


Berdasarkan table.2 mayoritas jenis kelamin responden adalah perempuan yaitu sebanyak 38 responden $(57,6 \%)$. Pada perempuan yang telah mengalami menopause memiliki potensi untuk terkena penyakit kardiovaskular, karena menurunnya hormone estrogen dan progesterone yang mengakibatkan mengerasnya arteri dan fleksibilitas kapiler (Kozier at,al, 2009)

Tabel 3

Distribusi Responden Berdasarkan Self management Di Puskesmas LimaPuluh Kota Pekanbaru

\begin{tabular}{llll}
\hline No & $\begin{array}{l}\text { Self } \\
\text { management }\end{array}$ & $\mathrm{f}$ & $\%$ \\
\hline 1 & Rendah & 18 & 27,3 \\
2 & Sedang & 44 & 66,7 \\
3 & Tinggi & 4 & 6 \\
\hline & Jml & 66 & 100 \\
\hline
\end{tabular}

Pada table 3 sebanyak $44(66,7 \%)$ menjalankan self managenet dalam katego ri sedang. meningkatkan kesehatan yang buruk. Penelitian The Royal Australian College of General Practioners (2010) bahwa perilaku self-management salah satunya dipengaruhi oleh motivasi, dimana motivasi seseorang akan dipengaruhi dan meningkat seiring dengan perubahan yang dialami oleh pasien.

Lee et al (2016) menyatakan bahwa secara umum self management merupakan proses menjaga kesehatan melalui keyakinan positif dan pengelolaan penyakit. Individu yang mengalami penyakit kronis, dapat melakukan self management melalui perawatan diri dalam mempertahankan kesehatan serta mengurangi efek dari penyakit dan membatasi perkembangan penyakit.

Self management merupakan serangkaian teknis untuk mengubah perilaku, pikiran, dan perasaan. Self management lebih menunjuk pada pelaksanaan dan penanganan kehidupan seseorang dengan menggunakan suatu keterampilan yang dipelajari. Self management juga dapat menghindarkan konsep inhibisi dan pengendalian dari luar yang seringkali dikaitkan dengan konsep kontrol dan regulasi. Self-management merupakan suatu strategi kognitif behavioural yang bertujuan untuk membantu klien agar dapat mengubah perilaku negatifnya dan mengembangkan perilaku positifnya dengan jalan mengamati diri sendiri; mencatat perilaku-perilaku tertentu (pikiran, perasaan, dan tindakannya). Teori self care management Orem mengidentifikasi sepuluh faktor dasar yang mempengaruhi self care agency dalam melakukan self management yaitu usia, gender, tahap perkembangan, tingkat kesehatan, pola hidup, sitem pelayanan kesehatan, keluarga dan lingkungan eksternal (Tomey \& Alligood, 2014).

Asumsi penelit pada masa pandemik Covid-19 dimana pasien dengan hipertensi merupakan penderita dengan penyakit penyerta yang sangat rentan terhadap penularan, maka self management atau perawatan terkait penyakit hipertensi sangat penting dilakukan untuk meminimalisir terjadinya penularan.

Tabel 3

Distribusi Responden Berdasarkan

Pengontrolan Tekanan Darah Di Puskesmas LimaPuluh Kota Pekanbaru

\begin{tabular}{cccc}
\hline No & Pengontrolan TD & $\mathrm{f}$ & $\%$ \\
\hline 1 & Terkontrol & 21 & 31,8 \\
& & & 68,2 \\
\hline & Tidak terkontrol & 45 & 100 \\
\hline
\end{tabular}

Dari hasil penelitian didapatkan mayoritas responden memiliki Pengontrolan Tekanan Darah yang tidak terkontrol yaitu sebanyak 45 responden (68,2\%). Menurut hasil penelitian (Tohari \& Soleha, 2016).Salah satu upaya untuk melakukan 
pencegahan komplikasi hipertensi perlu adanya peningkatan pencegahan tentang hipertensi. Perilaku mengontrol tekanan darah adalah aktivitas yang dilakukan oleh penderita hipertensi dalam mengontrol tekanan darah di pelayanan kesehatan. Namun, pasien hipertensi hanya melakukan kontrol ke pelayanan kesehatan apabila muncul tanda dan gejala bahkan jika sudah terjadi komplikasi seperti stroke (Rusmono, Hamzah Irwan, 2017)

Peneliti berasumsi kesadaran bagi penderita sangat berpengaruh bagi pentingnya menjaga kesehatan khususnya penderita hipertensi dengan pengontrolan tekanan darah secara rutin. Selain pengontrolan tekanan darah minum obat secara tertur akan mengurangi kekambuhan. Diketahui bahwa semakin tinggi tekanan darah maka semakin banyak komplikasi yang akan diakibatkan dan bersifat fatal bagi kesehatan. Selain kesadaran motivasi oleh keluarga juga sangat berpengaruh bagi penderita untuk melakukan kontrol tekanan darah dan memberitahukan apa saja yang tidak bisa dimakan oleh penderita hipertensi.

Asumsi peneliti pada masa pandemi Covid-19 pengontrolan tekanan darah yang dilakukan penderita hipertensi di Puskesmas sangat beresiko untuk tertular dengan pengunjung pasien yang lain. Sehingga pasien dengan hipertensi ketakutan bekunjung ke Puskesmas.

\section{KESIMPULAN}

1. Self management pada pasien hipertensi mayoritas kategori sedang 44 (66,7\%).

2. Pengontrolan Tekanan Darah pada pasien hipertensi mayoritas tidak terkontrol yaitu sebanyak 45 responden $(68,2 \%)$.

\section{UCAPAN TERIMA KASIH}

Terima kasih peneliti ucapkan atas bantuan dan bimbingan dari berbagai pihak dalam menyelesaikan penelitian ini.

\section{DAFTAR PUSTAKA}

Agastia, Nurhesti, Managkot, (2020), hubungan self-efficacy dengan selfmanagement behaviour pada pasien hipertensi di wilayah kerja Puskesmas III Denpasar Utara, Jurnal Community of Publishing in Nursing (COPING) Vol 8 No1. Diakses 23 Agustus

2020file://C:/Users/user/Downloads/5 9604-457-150035-1-10-20200508.pdf.

Alligood, MR \& Tomey AN. (2014) Nursing Theorist and Their Work, Sixth Edition, St. Louis Mosby

Andria,K,M, (2013), Hubungan Antara Prilaku Olah Raga, Stress, dan Pola Makan dengan Tingkat Hipertensi pada Lansia di Posyandu Lansia Kelurahan Gebang Putih Kecamatan Sukolilo Kota Surabaya SURABAYA, Jurnal Promkes, diakses 16 Juni 2021, Vol. 1, No. 2 Desember 2013: 111117.

Arista, (2013) Faktor Kepatuhan Diet Pasien Hipertensi, Jurnal Kesehatan Masyarakat. Diakses 8 Agustus 2020 $\begin{array}{lllll}\text { Vol } & 9 & \text { no } & 1 & \text { : }\end{array}$ http://journal.unnes.ac.id/nju/index.php /kemas.

Brillianti. (2016). Hubungan selfmanagement dengan kualitas hidup pasien pasca stroke di wilayah puskesmas pisangan ciputat. Diakses $20 \quad$ Agustus 2020 https://repository.uinjkt.ac.id 
Faraby, (2020), Tim Kuratif gugus tugas percepatan penanganan COVID 19 di Jawa Timur. Ada Penyakit Penyebab Utama Kematian Akibat COVID 19 di Jawa Timur. Diakses 3 oktober 2020 http://Surabaya.liputan6.com

Harsimi,(2020), Resiko Penyakit Berdasarkan Klasifikasi Umur menurut WHO, Diakses 23 Agustus 2020. https://www.sehatq.com.

Herawati, Wahyuni, (2016). Manfaat Latihan Pengaturan Pernafasan Untuk Menurunkan Tekanan Darah Pada Penderita Hipertensi Primer. Jurnal UMS The 3rd Universty Research Colloquium 2016. Diakses 23 Agustus 2020.

https://publikasiilmiah.ums.ac.id/bitstr eam/handle/11617/6703/9

Kozier, Barbara at.all (2009), Fundamental of nursing cincept, process and practice seventh edition, person education, new jersey

Lestari, I. G., Isnaini, N., Keperawatan, D., Kesehatan, F. I., \& Purwokerto, U. M. (2018). Pengaruh Self Managemen terhadap tekanan darah, 02(01), 7-18.

Lin, et al. (2018). Development and testing of the diabetes selfmanagementinstrument: $\quad A$ confirmatory analysis. Research in Nursing \& Health, 31, 370-380

Nugraheny,Dian, Erika, (2020), Up date 19 Juni:Kasus covid 19 tembus 80.
200.Diakses 19 Juni 2020, https://nasional.kompas.com.

Riskesdas. (2018). Laporan riset kesehatan dasar (riskesdas). Jakarta:Departemen Kesehatan Republik Indonesia

Rusmono, Hamzah Irwan, (2017), Hubungan Prilaku mengontrol Tekanan Darah Dengan kejadian Hipertensi, Jurnal Ilmiah Kesehatan Pencerah Vol 6 No2, diakses 20 Agustus 2020. file://C:/Users/user/Downloads/94Article\%20Text-150-1-1020190708.pdf

Rokom, (2021), 132 Persen Pasien-Covid19 Meninggal Memiliki-Penyakit Hipertensi, Diakses 21 Januari 2021. https://sehatnegeriku.kemkes.go.id

Sugiyono. (2017). Metode Penelitian Kuantitatif, Kualitatif, dan R\&D. Bandung : Alfabeta, CV.

Tohari, Soleha, (2016), Gambaran Keteraturan Mengontrol Tekanan Darah Pada Pasien Dengan Hipertensi Di Puskesmas Kedurus Surabaya, Jurnal Ilmiah Kesehatan Vol 9 No1. Diakses tgl 20 Agustus 2020, https://journal2.unusa.ac.id

Yahya, Achmad, Nasrudin, (2020).Up Date 7 Agustus : Kasus Suspek Covid 19 tembus 80.200. Diakses 7 Agustus 2020, https://nasional.kompas.com.

Word Health Organization (WHO). (2015). Prevalence of raised blood pressure. Dari:http://gamapserver.who.int/ gho/interactive_charts/ncd/risk_f actors/bl 